\title{
How Often Does Patient-Ventilator Asynchrony Occur and What Are the Consequences?
}

\author{
Scott K Epstein MD
}

\author{
Introduction \\ Factors to Consider in Analyzing the Prevalence of Patient-Ventilator \\ Asynchrony \\ Detecting Patient-Ventilator Asynchrony \\ How Often Does Patient-Ventilator Asynchrony Occur? \\ Effect of Patient-Ventilator Asynchrony on Outcomes \\ Summary
}

\begin{abstract}
Mechanical ventilation can be life-saving for patients with acute respiratory failure. In between the 2 extremes of complete and no ventilatory support, both patient and machine contribute to ventilatory work. Ideally, ventilator gas delivery would perfectly match patient demand. This patientventilator interaction depends on how the ventilator responds to patient respiratory effort and, in turn, how the patient responds to the breath delivered by the ventilator. It is now evident that the interaction between patient and ventilator is frequently suboptimal and that patient-ventilator asynchrony is common. Its prevalence depends on numerous factors, including timing and duration of observation, technique used for detection, patient population, type of asynchrony, ventilation mode and settings (eg, trigger, flow, and cycle criteria), and confounding factors (eg, state of wakefulness, sedation). Patient-ventilator asynchrony is associated with adverse effects, including higher/wasted work of breathing, patient discomfort, increased need for sedation, confusion during the weaning process, prolonged mechanical ventilation, longer stay, and possibly higher mortality. Whether asynchrony is a marker of poor prognosis or causes these adverse outcomes remains to be determined. Key words: patient-ventilator asynchrony; trigger asynchrony; mechanical ventilation; weaning. [Respir Care 2011;56(1):25-35. (C) 2011 Daedalus Enterprises]
\end{abstract}

\section{Introduction}

Mechanical ventilation can be life-saving for patients with acute respiratory failure. Once established, the objec-

\footnotetext{
Scott K Epstein MD is affiliated with the Office of Educational Affairs, and with the Division of Pulmonary, Critical Care and Sleep Medicine, Tufts Medical Center, Tufts University School of Medicine, Boston, Massachusetts.
}

The author has disclosed no conflicts of interest.

Dr Epstein presented a version of this paper at the 46th RESPIRATORY CARE Journal Conference, "Patient-Ventilator Interaction," held March 1921, 2010, in Cancún, Quintana Roo, Mexico. tive of mechanical ventilation should be to assume the work of breathing (WOB), improve gas exchange (increase $\mathrm{P}_{\mathrm{aO}_{2}}$ and decrease $\mathrm{P}_{\mathrm{aCO}}$ ), and unload the respiratory muscles. Animal studies have demonstrated that insufficient unloading may lead to considerable structural injury to the respiratory muscles. ${ }^{1,2}$ Therefore, some degree of ventilatory support is essential, especially during the initial phases of recovery from respiratory failure. Synchronization between ventilator and patient is virtually assured at times of

Correspondence: Scott K Epstein MD, Office of Educational Affairs, Tufts University School of Medicine, 136 Harrison Avenue, Sackler 317, Boston MA 02111. E-mail: scott.epstein@tufts.edu. 
total ventilatory support (eg, during paralysis or heavy sedation), when the patient is completely passive and makes no respiratory efforts. Unfortunately, if this excessive unloading persists beyond 24 hours, respiratory muscle injury can result (ventilator-induced diaphragmatic dysfunction). ${ }^{3,4}$ In between the 2 extremes of complete and no ventilatory support, both patient and machine contribute to ventilatory work. Ideally, ventilator gas delivery would perfectly match patient demand. This patient-ventilator interaction depends on how the ventilator responds to patient respiratory effort and, in turn, how the patient responds to the breath delivered by the ventilator. ${ }^{5}$ It is now evident that the interaction between patient and ventilator is frequently suboptimal, with consequences that appear to have substantial clinical relevance. ${ }^{6}$ Indeed, some authors have referred to this state as a "tug-of-war." A number of terms have been used to describe suboptimal interaction between patient and ventilator. In this paper the term "patient-ventilator asynchrony" will be used to describe any condition where the patient-ventilator interaction is not optimal.

Given the complexity of the respiratory system and of the ventilator, it is little wonder that patient-ventilator asynchrony is common. Either patient-related factors or ventilator-related factors may be responsible, and it is often the interaction between the two that results in asynchrony. ${ }^{5,6,8,9}$ Patient-related factors include respiratory mechanics (resistance, elastance, or dynamic hyperinflation/intrinsic PEEP), minute ventilation $\left(\dot{\mathrm{V}}_{\mathrm{E}}\right)$, respiratory muscle capacity, and respiratory drive. The latter are influenced by chemical and mechanical feedback loops, respiratory reflexes, and cortical influences. Ventilator factors include the method of inspiratory triggering (flow, pressure, wave shape, electrical activity of the diaphragm); site of triggering (ventilator, trachea, esophagus, diaphragm); inspiratory flow delivery (flow rate and pattern); breath-termination (cycling) criteria; level and mode (eg, pressure or volume control) of ventilatory support; and applied PEEP. In addition, the interface (endotracheal tube with invasive ventilation, or mask with noninvasive ventilation [NIV]) and the ventilator circuitry and humidification system (eg, heat-and-moisture exchanger) can contribute to patientventilator asynchrony. ${ }^{10}$

\section{Factors to Consider in Analyzing the Prevalence of Patient-Ventilator Asynchrony}

In determining the prevalence of patient-ventilator asynchrony it is important to distinguish between different types of asynchrony (Table 1). The largest body of data concerns inspiratory triggering asynchrony, with the most common form being ineffective efforts (also known as ineffective triggering, untriggered breaths, or trigger asynchrony), in which the patient's inspiratory effort fails to trigger the ventilator. Physiologically this event is characterized by an
Table 1. Type of patient-ventilator asynchrony

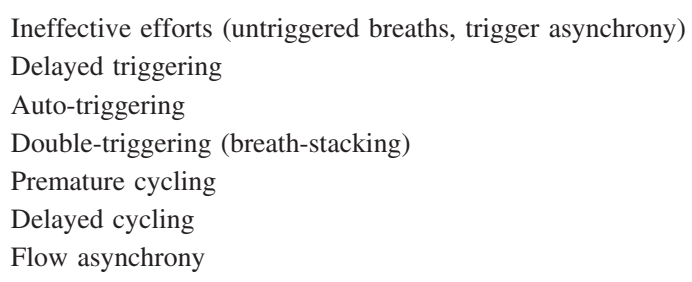

increase in transdiaphragmatic pressure (fall in esophageal pressure, increase in gastric pressure) and/or electrical activity of the diaphragm that does not result in a machinedelivered breath. Ineffective efforts can be detected by careful inspection of the flow-time and pressure-time tracings available on most ventilators. This ability to detect ineffective efforts noninvasively probably explains why they have been so extensively studied. A common definition of an ineffective effort (during the expiratory period) is an abrupt decrease in airway pressure (usually $>0.5 \mathrm{~cm} \mathrm{H}_{2} \mathrm{O}$ ) with a simultaneous decrease in expiratory flow, not resulting in an assisted breath from the ventilator. ${ }^{11}$ The vast majority of ineffective efforts are detected during mechanical expiration. Ineffective efforts can also occur during inspiration, where they are characterized by an abrupt increase in inspiratory flow (during pressuresupport ventilation [PSV]) or a transient abrupt decrease in airway pressure (during volume-controlled continuous mandatory ventilation [VC-CMV]) without triggering a full additional breath. Ineffective efforts may result from dynamic hyperinflation (intrinsic PEEP), reduced respiratory drive (including from excessive sedation), respiratory muscle weakness, or an insensitive trigger setting on the ventilator. ${ }^{10}$

Double-triggering refers to the occurrence of 2 consecutive inspirations with an interval of less than half of the mean inspiratory time $\left(\mathrm{T}_{\mathrm{I}}\right) \cdot{ }^{11}$ Double-triggering can occur when respiratory drive is high, delivered ventilatory support is insufficient (eg, tidal volume $\left[\mathrm{V}_{\mathrm{T}}\right]$ or $\dot{\mathrm{V}}_{\mathrm{E}}$ too low), and neural $T_{I}$ is longer than the $T_{I}$ set on the ventilator.

Auto-triggering refers to an unscheduled machine-delivered breath that occurs in the absence of patient effort. The absence of patient triggering can be inferred by the absence of a decrease in airway pressure prior to the machine-delivered breath. Auto-triggering is most definitively detected when esophageal pressure and diaphragmatic electromyogram reveal a "triggered" breath in the absence of respiratory muscle activity. Auto-triggering may occur when the triggering threshold (pressure or flow) is too sensitive or in the presence of circuit leaks, water in the circuit (creating flow transients), or vigorous cardiac oscillations. ${ }^{12,13}$ The latter may occur in a young patient with a high stroke volume. Auto-triggering is typically seen when respiratory drive is low, respiratory rate in low, and 
when there is no intrinsic PEEP. As can be appreciated, ensuring good patient-ventilator synchrony is a balancing act. For example, to minimize triggering work and reduce ineffective efforts, the trigger sensitivity should be set as sensitive as possible. Yet if it is set too sensitive, autotriggering will result, though ineffective efforts may disappear. ${ }^{14}$

Another form of trigger asynchrony entails delayed triggering, where the patient is able to trigger a breath but gas flow delivery is abnormally delayed. Trigger delay was a considerable problem with older ventilators, but technological advances have substantially improved ventilator response time, though considerable variability exists between ventilators. ${ }^{15,16}$

Flow asynchrony can occur when the inspiratory flow (inspiratory pressure rise time) is insufficient to meet the patient's ventilatory demand. Flow asynchrony will improve when fixed inspiratory flow is increased or the patient is changed to a pressure-control or variable-flow mode. ${ }^{17-19}$ This phenomenon can be readily detected by inspecting the flow-time waveform. ${ }^{20}$ Flow asynchrony distorts the curve, which now assumes a concave appearance toward the flow (Y) axis. Indeed, by computing the area under the flow-volume or flow-time curve and comparing it to that of a passive breath (which produces a concave-upward curve), one can estimate patient WOB. ${ }^{18}$ It is important to remember that this form of asynchrony, a post-triggering event, can occur even though the $T_{I}$ is well matched between patient and ventilator.

Patient-ventilator asynchrony can occur when there is poor matching between neural (patient) and mechanical (ventilator) $\mathrm{T}_{\mathrm{I}}{ }^{21}$ For example, if mechanical $\mathrm{T}_{\mathrm{I}}$ lasts longer than neural $T_{I}$, the patient initiates expiration while the ventilator continues to deliver gas. Conversely, when neural $T_{I}$ exceeds mechanical $T_{I}$, the patient continues in an inspiratory effort but the ventilator has cycled to expiration. This cycle asynchrony is dependent on many factors, but most importantly on the criteria that initiate mechanical cycling to expiration. Cycling asynchrony may manifest as a "premature cycle," where the $\mathrm{T}_{\mathrm{I}}$ is less than $50 \%$ of the mean $\mathrm{T}_{\mathrm{I}}$, or a "prolonged cycle," where the $\mathrm{T}_{\mathrm{I}}$ exceeds twice the mean $\mathrm{T}_{\mathrm{I}} \cdot{ }^{11}$

\section{Detecting Patient-Ventilator Asynchrony}

In assessing how often asynchrony occurs, one must consider a number of factors (Table 2). Was the patient observed once or more than once, and how long was the observation period? Given that patient-ventilator asynchrony is an episodic or intermittent phenomenon, very short observation periods may fail to detect asynchrony that would be observed during longer study periods, so multiple observation points will probably yield a higher prevalence. Given that patient-related factors are so im-
Table 2. Factors to Consider in Determining How Often PatientVentilator Asynchrony Occurs

\begin{tabular}{l}
\hline \hline Timing of observations \\
Duration of observations \\
Method of detection \\
Esophageal pressure \\
Electrical activity of the diaphragm \\
Waveform analysis \\
Type of asynchrony \\
Definition of "significant" \\
Patient population \\
Type of mechanical ventilation \\
Invasive versus noninvasive \\
Pressure or volume targeted \\
Ventilation mode (conventional vs newer modes) \\
Triggering method \\
Cycling method \\
Degree of ventilatory support \\
Additional factors \\
Sedation \\
\hline
\end{tabular}

portant and these factors change over time, one would predict that different levels of asynchrony would be detected during the first 24 hours of mechanical ventilation, compared to day 3 , day 7 , day 14 , etc.

The asynchrony detection method will determine the prevalence. The accepted standard for detection includes measurement of esophageal pressure and/or electrical activity of the respiratory muscles (eg, diaphragm, transverse abdominus).5,22,23 These techniques allow for definitive confirmation of respiratory muscle activity and allow precise determination of neural inspiratory and expiratory time. Detection using ventilator waveform analysis may lead to underestimation or overestimation of the amount of asynchrony. In the former instance, respiratory muscle contraction may be insufficient to result in a detectable change in pressure or flow, so patient effort goes undetected and asynchrony is underestimated. In a study with 21 patients, $20 \%$ of ineffective efforts were not detected via waveform analysis. ${ }^{24}$ In another study, ineffective efforts during the expiratory phase, detected via automated analysis of airflow and pressure deflections, had a sensitivity of $91 \%$ and specificity of $96 \%$ (the accepted standard method was esophageal balloon). ${ }^{25}$ Alternatively, factors other than respiratory muscle action (eg, airway secretions, cardiac oscillations) may result in apparent changes in flow or pressure, and asynchrony is overestimated.

The ventilation mode can influence the prevalence of patient-ventilator asynchrony. For example, patients on PSV and VC-CMV have higher asynchrony rates than patients on newer modes such as neurally adjusted ventilatory assist (NAVA) or proportional assist ventilation. ${ }^{24,26,27}$ For example, the improved synchrony with NAVA probably relates to using the crural diaphragmatic 
electromyographic signal to trigger and cycle the ventilator. Not only is the ventilation mode important: how that mode is applied is crucial. Some ventilators allow adjustment of the expiratory cycling criteria, to improve neural/ machine $T_{I}$ matching. As an example, in patients with obstructive lung disease, changing the cycle criterion to a higher percentage of peak inspiratory flow (ie, earlier cycling) decreased the number of ineffective efforts and improved patient-ventilator interaction. ${ }^{28,29}$ But the issue is complex. In patients with acute lung injury (ie, short time constant), changing the cycling criteria to promote earlier transition to expiration actually increases WOB and promotes double-triggering, even though ineffective efforts may diminish. ${ }^{30,31}$ The degree of ventilatory support (machine-delivered $\mathrm{V}_{\mathrm{T}}$ and $\dot{\mathrm{V}}_{\mathrm{E}}$ ) is important: higher values are associated with increases in some forms of asynchrony (eg, ineffective efforts). This may occur secondary to decreased respiratory drive or, in patients with air-flow obstruction, worsening dynamic hyperinflation, in whom synchrony improves when the ventilatory support is diminished. Conversely, in other forms of respiratory failure (eg, acute lung injury) insufficient ventilatory support may lead to a different form of asynchrony (eg, doubletriggering, also known as breath-stacking). ${ }^{32}$ NIV interfaces are prone to patient-ventilator asynchrony because mask leak influences flow-cycling. ${ }^{33}$

The patient population can influence the amount of asynchrony. For example, ineffective efforts and cycle asynchrony would be expected to be relatively common in COPD patients, who have considerable dynamic hyperinflation (intrinsic PEEP). ${ }^{7}$ Similarly, patients with respiratory muscle weakness or decreased respiratory drive should have more ineffective efforts. Conversely, patients with acute lung injury and high respiratory drive will have fewer ineffective efforts but more double-triggering. This again highlights the difficult balancing act the clinician experiences in setting the ventilator.

\section{How Often Does Patient-Ventilator Asynchrony Occur?}

Numerous studies have directly examined the prevalence of patient-ventilator asynchrony. In analyzing these investigations it is important to keep in mind the factors mentioned above that may influence the observed prevalence.

Building on earlier work, ${ }^{34,35}$ Fabry and colleagues ${ }^{36}$ were among the first to suggest that patient-ventilator asynchrony was very common in patients intubated for acute respiratory failure. They analyzed esophageal pressure waveforms from 11 patients ( 3 with COPD) once the patients were able to trigger the ventilator (mean $3.8 \mathrm{~d}$ after intubation). They used an esophageal balloon to identify asynchrony, defined as ineffective efforts. The patients

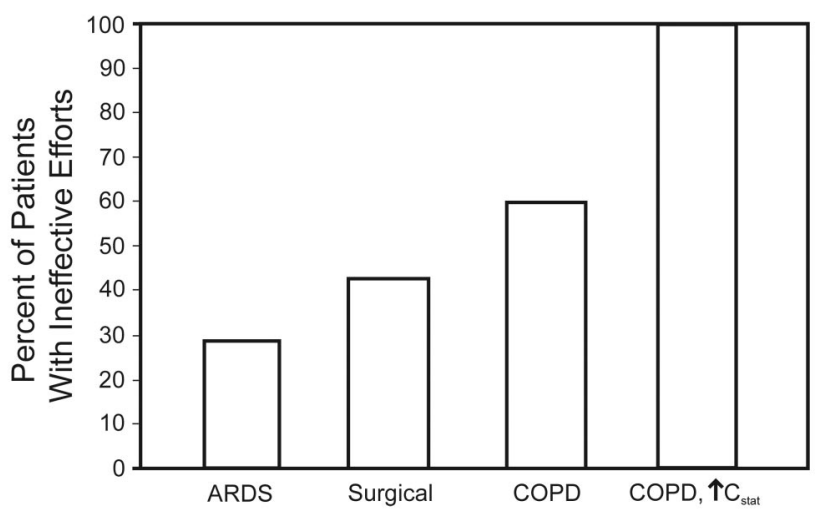

Fig. 1. Percentage of patients with ineffective efforts, relative to disease category. COPD, $\uparrow \mathrm{C}_{\text {stat }}=\mathrm{COPD}$ and elevated static compliance. (From data in Reference 37.)

were studied for 5 min after each decrease in the pressuresupport level. Nine patients $(82 \%)$ demonstrated ineffective efforts, in $2-40 \%$ of all breaths. Seven patients had substantial asynchrony, defined as $\geq 10 \%$ of breaths untriggered. This $10 \%$ failed efforts threshold (or index) was subsequently adopted by investigators as an indicator of substantial asynchrony.

As discussed by Fabry, patients with COPD may be at highest risk for patient-ventilator asynchrony because of the presence of dynamic hyperinflation and intrinsic PEEP. Nava and colleagues also studied patients ventilated for at least 48 hours, with various causes of acute respiratory failure. ${ }^{37}$ Twenty-four patients were studied for 5 minutes each, on PSV, and the measurements were via esophageal and gastric balloons. Thirteen patients (54\%) demonstrated ineffective efforts, and ineffective efforts were more common in COPD patients (Fig. 1), especially in COPD patients with increased static compliance $\left(>88 \mathrm{~mL} / \mathrm{cm} \mathrm{H}_{2} \mathrm{O}\right)$.

In the most comprehensive investigation to date, Thille et al studied 62 patients (26\% with COPD) intubated for acute respiratory failure. ${ }^{11}$ Fifty-one patients $(82 \%)$ were ventilated with pressure support, and $11(18 \%)$ with VCCMV. Pressure support was set to yield a $\mathrm{V}_{\mathrm{T}}$ of $6-8 \mathrm{~mL} / \mathrm{kg}$ with a respiratory rate of $<30$ breaths/min, and a cycle criterion of $25 \%$ of peak inspiratory flow. VC-CMV was set for a $\mathrm{V}_{\mathrm{T}}$ of $6-8 \mathrm{~mL} / \mathrm{kg}$ and an inspiratory flow rate of $60 \mathrm{~L} / \mathrm{min}$. Each patient was studied in one 30-min observation period, after they were able to trigger a breath $(4.5 \mathrm{~d}$ after intubation, interquartile range 3-7 d). Patient-ventilator asynchrony was determined via graphic analysis of pressure-time and flow-time curves. An ineffective effort was defined as an abrupt airway-pressure decrease of at least $0.5 \mathrm{~cm} \mathrm{H}_{2} \mathrm{O}$ with a simultaneous decrease in expiratory flow that did not result in a patient-triggered breath. Two blinded investigators examined each tracing and had strong agreement (kappa 0.96). In 11 patients an esophageal balloon was placed, and the number of asynchrony 
events closely correlated (0.99) with the findings from "noninvasive" graphic analysis. Overall, there was a median of 2.1 asynchronous breaths per minute (interquartile range 0.7-8.6). Eighty-five percent of the asynchronous events were ineffective efforts, $13 \%$ were double-triggered breaths, and the remainder were attributed to auto-triggering and premature and delayed cycle breaths. Ninety percent of the ineffective efforts occurred during expiration, $10 \%$ during inspiration. Fifteen patients (24\%) had an asynchrony index of $>10 \% ; 11$ had $>10 \%$ ineffective efforts; and 4 had $>10 \%$ double-triggering. The factors associated with $>10 \%$ ineffective efforts were higher pressuresupport level, lower trigger sensitivity, higher peak inspiratory pressure, higher inspired $\mathrm{V}_{\mathrm{T}}$, higher serum $\mathrm{pH}$, and COPD. Double-triggering was more common with VC-CMV, lower $\mathrm{P}_{\mathrm{aO}_{2}} / \mathrm{F}_{\mathrm{IO}_{2}}$, higher maximum inspiratory pressure, and shorter $\mathrm{T}_{\mathrm{I}}$.

Thille et al subsequently demonstrated the importance of pressure-support level in a study with 12 patients (6 with COPD) with an asynchrony (ineffective effort) index $>10 \%$ (mean 45\%). ${ }^{38}$ Adjusting PEEP did not affect the number of ineffective efforts, but reducing the mean pressure support from $20 \mathrm{~cm} \mathrm{H}_{2} \mathrm{O}$ (mean $\mathrm{V}_{\mathrm{T}} 10.2 \mathrm{~mL} / \mathrm{kg}$ ) to $13 \mathrm{~cm} \mathrm{H}_{2} \mathrm{O}$ (mean $\mathrm{V}_{\mathrm{T}} 5.9 \mathrm{~mL} / \mathrm{kg}$ ) significantly reduced the number of ineffective efforts. Indeed, at the lower PSV level, ineffective efforts were completely abolished in 8 patients. This finding emphasizes the potential influence of the pressure-support level on the prevalence of asynchrony.

This observation was also evident in the work of Jubran et al in their study with 12 patients with COPD. ${ }^{39} \mathrm{~A}$ higher pressure-support level was associated with higher esophageal pressure during expiration. When the pressure-support level was $20 \mathrm{~cm} \mathrm{H}_{2} \mathrm{O}, 5$ of the 12 patients had evidence of expiratory muscle recruitment during the inflation phase. In other words, neural $\mathrm{T}_{\mathrm{I}}$ was shorter than machine $\mathrm{T}_{\mathrm{I}}$ (ie, machine inspiration encroached upon neural expiration). Delaying expiratory emptying of the lung worsens dynamic hyperinflation, which may precipitate ineffective efforts. This is an example of "asynchrony begetting asynchrony."

What about other conventional modes of mechanical ventilation? Leung and coworkers studied 11 patients (8 with COPD) and found that ineffective efforts occurred with several different ventilation modes and were dependent on the degree of ventilatory support. ${ }^{40}$ A high pressure-support level, volume-controlled intermittent mandatory ventilation (VC-IMV), and PSV plus VC-IMV were all associated with substantial numbers of ineffective efforts. With 100\% VC-IMV support (ie, when VC-IMV was set to provide the full predicted $\dot{\mathrm{V}}_{\mathrm{E}}$, without spontaneous breaths), $29 \%$ of all efforts were ineffective, whereas at $100 \%$ pressure support (mean $17 \mathrm{~cm} \mathrm{H}_{2} \mathrm{O}$ ), 26\% of efforts were ineffective. Reducing the pressure-support level to below $60 \%$ significantly decreased the number of

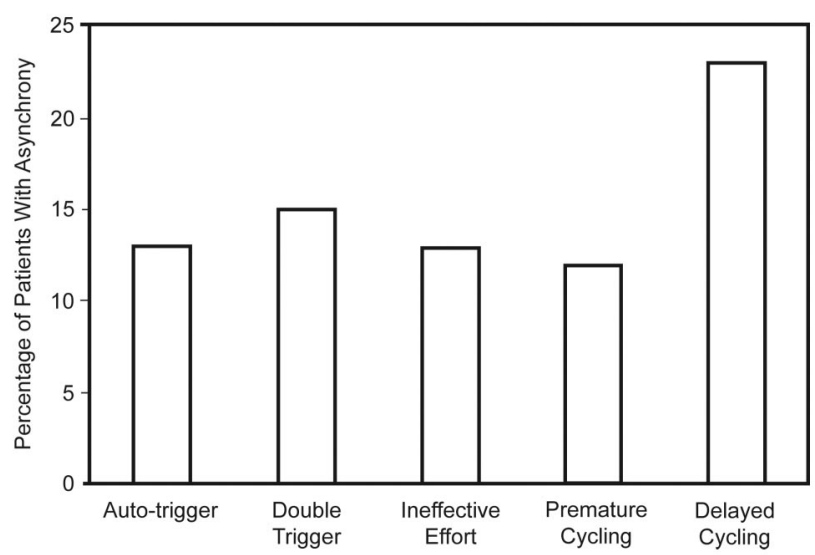

Fig. 2. Percentage of patients (treated with noninvasive ventilation for acute respiratory failure) with 5 types of patient-ventilator asynchrony. (From data in Reference 42.)

ineffective efforts. Leung et al noted that breaths preceding an ineffective effort were characterized by higher $\mathrm{V}_{\mathrm{T}}$, shorter expiratory time, and higher intrinsic PEEP.

Although decreasing the degree of ventilatory support reduces the amount of ineffective triggering, it can also increase the amount of double-triggering, especially when respiratory drive is high. Double-triggering may be particularly common in patients ventilated with low $\mathrm{V}_{\mathrm{T}}$. Pohlman et al studied (for a mean of 3.3 d) 20 patients with acute lung injury who were ventilated with the Acute Respiratory Distress Syndrome (ARDS) Network low- $\mathrm{V}_{\mathrm{T}}$ protocol $(6 \mathrm{~mL} / \mathrm{kg}$ ideal body weight $){ }^{41}$ Double-triggers (stacked breaths) occurred in $9.7 \%$ of all breaths (2.3 per minute). One third of the time, more than 3 stacked breaths per minute were detected, and $45 \%$ of patients had at least 12 hours of $>6$ stacked breaths per minute. Stacked breaths were less common with higher $\mathrm{V}_{\mathrm{T}}$.

In 3 centers, Vignaux and colleagues examined, during one 30-min observation per patient, the frequency of patient-ventilator asynchrony in patients with acute respiratory failure who received NIV via intensive care unit (ICU) ventilators. ${ }^{42}$ The patients were studied for a mean 1.3 days after initiation of NIV, and had a heterogeneous group of diseases, including COPD (40\%), congestive heart failure $(28 \%)$, obesity-hypoventilation syndrome (15\%), restrictive lung disease (7\%), and neuromuscular disease $(5 \%)$. Fifty-five percent of the patients were hypercapnic. Asynchrony was detected frequently (Fig. 2), and $43 \%$ had an asynchrony index $>10 \%$. The magnitude of mask leak (expressed in $\mathrm{L} / \mathrm{min}$ or percentage of $\mathrm{V}_{\mathrm{T}}$ ) was associated with both ineffective efforts and delayed cycling. In multivariate analysis, both the magnitude of leak and higher pressure-support level were associated with an asynchrony index $>10 \%$. Similar results were reported by Mulqueeny et al, who found that $40 \%$ of patients receiving NIV had an asynchrony index $>10 \% .43$ 
Newer ventilation modes may reduce asynchrony, so studies employing newer modes may report a lower prevalence of asynchrony. For example, a crossover study with 14 patients ventilated for 2-16 days for acute respiratory failure compared PSV to NAVA. ${ }^{44}$ Five $(36 \%)$ of 12 patients on PSV had $>10 \%$ ineffective efforts, whereas no patient on NAVA had $>10 \%$ ineffective efforts. In 14 patients (12 with COPD) ventilated for acute respiratory failure, NAVA abolished ineffective efforts in 6 patients on PSV. ${ }^{45}$ Similarly, when compared to PSV, proportional assist ventilation reduced the number of ineffective efforts. ${ }^{26}$ In a study with 218 critically ill patients, fewer patients randomized to proportional assist ventilation experienced major patient-ventilator asynchrony than those treated with PSV (5.6\% vs $29 \%) .{ }^{46}$

The timing of observation may be important in determining the prevalence of asynchrony. The studies examined above generally observed patients after at least 24 hours of mechanical ventilation, but typically within the first week. In a study with 60 medical ICU patients intubated for acute respiratory failure and ventilated on either PSV or PSV plus VC-IMV, de Wit and coworkers used waveform analysis to identify the ineffective efforts in one 10min period per patient. They found an asynchrony index $>10 \%$ in 16 patients $(27 \%)$ during the first 24 hours of mechanical ventilation (mean $13 \mathrm{~h}$ ). ${ }^{47}$

What about the prevalence of asynchrony in those undergoing prolonged mechanical ventilation? Chao and colleagues studied 174 patients (45\% with COPD) transferred to a regional weaning center after an average of 29 days of mechanical ventilation. ${ }^{48}$ At the time of study, all the patients were ventilated with VC-CMV via tracheostomy. Patients were studied for a minimum of 2 minutes within 7 days of transfer. Nineteen patients $(11 \%)$ demonstrated ineffective efforts, and a mean of $45 \%$ of breaths were untriggered. When compared to those without ineffective efforts, those with ineffective efforts were older ( $75 \mathrm{y}$ vs 69 y), more likely to have COPD ( $84 \%$ vs $40 \%$ ), had a higher $\mathrm{P}_{\mathrm{aCO}}(52 \mathrm{~mm} \mathrm{Hg}$ vs $45 \mathrm{~mm} \mathrm{Hg}$ ), and had a less negative maximum inspiratory pressure $\left(-16 \mathrm{~cm} \mathrm{H}_{2} \mathrm{O}\right.$ vs $-29 \mathrm{~cm} \mathrm{H}_{2} \mathrm{O}$ ). Chao et al found that adjustments to trigger sensitivity and changing to flow-triggering did not reduce the level of asynchrony. Addition of extrinsic PEEP only transiently reduced ineffective efforts. Both reducing the pressure-support level to a mean of $11 \mathrm{~cm} \mathrm{H}_{2} \mathrm{O}$ and decreasing $\mathrm{V}_{\mathrm{T}}$ in VC-CMV eliminated asynchrony. Ineffective efforts during sleep were eliminated by arousing the patient, which further highlights the timing of observation. For example, Fanfulla et al, in a study with 48 patients (with COPD, obesity hypoventilation syndrome, or kyphoscoliosis) on prolonged mechanical ventilation, found no ineffective efforts during daytime ventilation, ${ }^{49}$ and $4 \%$ ineffective efforts during sleep (at the same ventilator set- tings). Other investigators have found that patient-ventilator asynchrony can cause sleep disruption. ${ }^{50}$

In another study with patients on prolonged mechanical ventilation, Vitacca et al examined 36 tracheostomized patients transferred to their regional weaning unit after a mean of 30 days of mechanical ventilation. ${ }^{51}$ Twenty patients had COPD, 8 had postoperative respiratory failure, and 8 had neuromuscular disease. Asynchrony was determined by analyzing waveforms at 12 different time points. Twenty-six patients (72\%) had ineffective efforts. As in previous studies, ineffective efforts were more common with a higher pressure-support level. In this study, applied PEEP of $5 \mathrm{~cm} \mathrm{H}_{2} \mathrm{O}$ did not reduce the number of ineffective efforts. Of note, similar percentages of patients exhibited ineffective efforts in each of the 3 patient types.

Finally, other ICU interventions can affect the prevalence of asynchrony. de Wit et al studied 20 medical ICU patients with acute respiratory failure ventilated with either PSV or VC-IMV plus pressure support. ${ }^{52}$ Asynchrony was determined during up to three 15-min observation periods, via waveform analysis. All patients demonstrated asynchrony (mean $11 \%$ of breaths): ineffective efforts were seen in $85 \%$ of patients, double-triggering in $50 \%$, premature cycling in $60 \%$ and delayed cycling in 5\%. Among all recorded asynchronous breaths, $88 \%$ were ineffective, $6 \%$ were double-triggered, and $6 \%$ were short-cycle. One in 5 patients had an asynchrony index $>20 \%$. Ineffective triggering was associated with higher levels of sedation, as assessed with the Richmond Agitation-Sedation Score, the Confusion Assessment Method, and the ability to follow 4 simple commands. This study points out the importance of confounding factors (eg, sedation) in assessing the prevalence of asynchrony.

\section{Effect of Patient-Ventilator Asynchrony on Outcomes}

As seen above, patient-ventilator asynchrony is common, depending on numerous factors, with a prevalence ranging as high as $80 \%$. But does it have an important effect on outcome? Circumstantial evidence and recent observational studies suggest that higher levels of patientventilator asynchrony are associated with poor outcome (Table 3).

During normal breathing the inspiratory muscles shorten while contracting. Although ineffective inspiratory efforts can occur either during the inspiratory or expiratory phase, $90 \%$ occur during the latter. ${ }^{11}$ During the expiratory phase the inspiratory muscles (eg, diaphragm) lengthen as lung volume decreases. Activation of the inspiratory muscles at this time may result in muscle contraction during lengthening. In skeletal limb muscle in animals, this type of contraction, termed eccentric or pliometric contraction, can lead to muscle fiber injury and decreased ability to gen- 
Table 3. Adverse Effects of Patient-Ventilator Asynchrony on Outcome

\begin{tabular}{l}
\hline Ultrastructural injury to respiratory muscles \\
Eccentric or pliometric contraction \\
Worsens mechanics ( $\uparrow$ intrinsic PEEP) \\
Alters gas exchange (auto-triggering $\rightarrow \downarrow \mathrm{P}_{\mathrm{aCO}_{2}}$ ) \\
Wastes respiratory work (unnecessary load) \\
Confounds lung-protective strategy (breath-stacking leads to increased \\
$\quad$ tidal volume) \\
Noninvasive ventilation $=\downarrow$ effectiveness and failure to tolerate \\
May cause periodic breathing, sleep fragmentation \\
Patient discomfort and dyspnea ( $\uparrow$ sedation) \\
Can confuse the clinician (weaning decision making)
\end{tabular}

erate force ${ }^{53,54}$ Whether this occurs in respiratory muscle remains to be proven.

Patient-ventilator asynchrony can worsen respiratory mechanics, thereby predisposing to further asynchrony. Double-triggering (breath-stacking) is associated with increased inspired $\mathrm{V}_{\mathrm{T}}$. In patients with expiratory air-flow limitation (eg, asthma and COPD) this predisposes to dynamic hyperinflation, leading to increased WOB (secondary to increased elastic load and creation of an inspiratory threshold load), diaphragmatic dysfunction, and ineffective efforts. A similar sequence of events may occur with delayed cycling (machine $\mathrm{T}_{\mathrm{I}}>$ neural $\mathrm{T}_{\mathrm{I}}$ ) ${ }^{21}$ In this case, encroachment of machine $T_{I}$ on neural expiratory time decreases expiration time, leading to air trapping and dynamic hyperinflation.

Patient-ventilator asynchrony can adversely affect oxygenation and gas exchange. The mechanisms described above may, by causing dynamic hyperinflation, culminate in ventilation-perfusion mismatch, leading to hypoxemia and hypercapnia. Auto-triggering, from increasing $\dot{\mathrm{V}}_{\mathrm{E}}$, can result in unwanted hypocapnia and alkalemia. Auto-triggered breaths can also give the impression that a patient has preserved respiratory drive and is triggering the ventilator. In one report this effect delayed the recognition of brain death. ${ }^{55}$

Ineffective efforts constitute wasted respiratory work, as the inspiratory muscles contract and consume oxygen but do not generate $\mathrm{V}_{\mathrm{T}}$ or $\dot{\mathrm{V}}_{\mathrm{E}}$. Unfortunately, respiratory motor output can be considerable, even if it fails to trigger a breath. ${ }^{40}$ This effect has been quantified in several studies. Nava et al studied 10 patients with COPD and found a higher pressure-support level to be associated with more ineffective efforts and wasted work, as indicated by an increased pressure-time product (PTP) of the diaphragm. ${ }^{56}$ Nava and colleagues subsequently measured WOB by measuring diaphragmatic PTP in 24 patients with acute respiratory failure ventilated on PSV. ${ }^{37}$ The diaphragmatic PTP per breath of the effective and ineffective efforts were very similar. In patients with ARDS the average diaphragmatic
PTP per breath was $5.77 \mathrm{~cm} \mathrm{H}_{2} \mathrm{O} \cdot \mathrm{s} / \mathrm{min}$, whereas it was $6.43 \mathrm{~cm} \mathrm{H}_{2} \mathrm{O} \cdot \mathrm{s} / \mathrm{min}$ in patients with COPD who had increased static compliance. This was striking because, on average, $95 \%$ of all ARDS breaths triggered the ventilator ( 23 of 24 breaths/min), whereas only 55\% of COPD breaths triggered the ventilator (11 of 20 breaths $/ \mathrm{min}$ ). In other words, the PTP per minute was the same $\left(1.35 \mathrm{~cm} \mathrm{H}_{2} \mathrm{O} \cdot \mathrm{s} /\right.$ $\min$ vs $1.37 \mathrm{~cm} \mathrm{H}_{2} \mathrm{O} \cdot \mathrm{s} / \mathrm{min}$ ) despite a much lower $\dot{\mathrm{V}}_{\mathrm{E}}$ in the COPD patients.

Leung and coworkers found the PTP was 38\% higher during ineffective efforts than during triggered breaths..$^{40}$ Thille and coworkers studied 12 patients (50\% with COPD) and found that greater than $10 \%$ of WOB was performed on ineffective inspiratory efforts..$^{38}$ On PSV with zero PEEP they found a PTP on ineffective breaths of $9 \mathrm{~cm} \mathrm{H}_{2} \mathrm{O} \cdot \mathrm{s} /$ min out of a total PTP of $76 \mathrm{~cm} \mathrm{H}_{2} \mathrm{O} \cdot \mathrm{s} / \mathrm{min}$. It is likely that the amount of wasted work associated with ineffective efforts depends on the underlying mechanism. Higher levels are likely when trigger sensitivity is set too high or intrinsic PEEP is present. Lower levels probably occur when the cause is excessive sedation or another process that decreases respiratory drive.

Effective management of acute lung injury requires a $\mathrm{V}_{\mathrm{T}}$ of $6 \mathrm{~mL} / \mathrm{kg} / \mathrm{min}$ to protect the lung from further lung injury. ${ }^{57}$ When compared to a $\mathrm{V}_{\mathrm{T}}$ of $12 \mathrm{~mL} / \mathrm{kg}$ predicted body weight, patients randomized to the lower $\mathrm{V}_{\mathrm{T}}$ had lower mortality. ${ }^{57}$ Yet the lower $\mathrm{V}_{\mathrm{T}}$ increases patient WOB. ${ }^{58}$ Patient-ventilator asynchrony can confound attempts to deliver a lung-protective strategy. Pohlman and colleagues found that breath-stacking occurred in one of every 10 breaths when $V_{T}$ was set at approximately $6 \mathrm{~mL} / \mathrm{kg}$ predicted body weight in patients with acute lung injury. ${ }^{41}$ The measured $\mathrm{V}_{\mathrm{T}}$ after a stacked-breath event was $10.1 \mathrm{~mL} / \mathrm{kg}$ predicted body weight. Whether this increased $\mathrm{V}_{\mathrm{T}}$, which occurred on average every 10 breaths, results in ventilator-induced lung injury remains to be determined.

Patient-ventilator asynchrony causes patient discomfort. Vitacca et al, in a study with patients ventilated for at least 30 days, noted both increasing ineffective efforts and increasing patient discomfort (measured with the Borg comfort scale) as the pressure-support level was increased from $15 \mathrm{~cm} \mathrm{H}_{2} \mathrm{O}$ to $30 \mathrm{~cm} \mathrm{H}_{2} \mathrm{O} .{ }^{51}$ In their study with patients on NIV, Vignaux et al found greater asynchrony (defined as an asynchrony index $>10 \%$ ) to be associated with less comfort, measured with a visual analog scale (5.7 vs 6.5, $P<.05) .{ }^{42}$ Whether it was the asynchrony itself or the associated greater leak that caused the discomfort remains to be determined.

Studies conducted over the last decade have convincingly demonstrated that sedation in the critically ill patient (especially when given continuously and intravenously) is associated with poor outcomes, including longer mechanical ventilation. ${ }^{59}$ Randomized controlled trials indicate that strategies designed to reduce delivered sedation, using 
an algorithm driven by a sedation scoring system or daily interruption of sedation, improved outcomes, though the best approach remains unknown. ${ }^{60-62}$ Patient-ventilator asynchrony is one of the most frequently cited indications for sedating ventilated patients. As an example, in a study by Pohlman et al, $42 \%$ of all increases in the amount of sedation were in response to patient-ventilator asynchrony. ${ }^{41}$ Indeed, the ARDS Network protocol for delivering low- $\mathrm{V}_{\mathrm{T}}$ ventilation directs the clinician to adjust the ventilator or administer sedation when there are $\geq 3$ stacked breaths per minute. ${ }^{57}$ As noted earlier, greater sedation is associated with increased risk of ineffective efforts. ${ }^{52}$

Many clinicians use the ratio of frequency (f) to $V_{T}$ to aid in weaning decision making, though its use has not been shown to improve outcome. ${ }^{63}$ Observational studies showed that lower $f / V_{T}$ is associated with weaning success, and higher $f / V_{T}$ is associated with weaning failure. As originally described by Yang and Tobin, the $\mathrm{f} / \mathrm{V}_{\mathrm{T}}$ measurement is made by disconnecting the patient from the ventilator and observing a 1-minute period of spontaneous breathing through a T-piece connected to a spirometer, ${ }^{64}$ and the respiratory rate is determined via physical examination and then divided by the calculated $\mathrm{V}_{\mathrm{T}}$ (in $\mathrm{L}$ ) to yield the $\mathrm{f} / \mathrm{V}_{\mathrm{T}}$ (eg, 30 breaths $/ \mathrm{min}$ at a $\mathrm{V}_{\mathrm{T}}$ of $0.6 \mathrm{~L}=$ 50 breaths $/ \mathrm{min} / \mathrm{L}$ ). In contrast, some clinicians leave the patient connected to the ventilator and calculate $f / \mathrm{V}_{T}$ with the respiratory rate measured by the ventilator. ${ }^{65}$ But because the ventilator does not detect ineffective efforts, the ventilator-measured respiratory rate will be lower than the true respiratory rate. As an example, if $\mathrm{V}_{\mathrm{T}}$ is $0.3 \mathrm{~L}$ and the ventilator-measured respiratory rate is 21 breaths/min, then $\mathrm{f} / \mathrm{V}_{\mathrm{T}}$ is 70 breaths $/ \mathrm{min} / \mathrm{L}$, which suggests that the patient is likely to pass a spontaneous breathing test.

In contrast, when one accounts for the ineffective efforts, suppose the actual respiratory rate is 45 breaths $/ \mathrm{min}$, which yields an $\mathrm{f} / \mathrm{V}_{\mathrm{T}}$ of 150 breaths $/ \mathrm{min} / \mathrm{L}$, which suggests that the patient is not ready for spontaneous breathing. Indeed, Purro and colleagues studied 20 patients with COPD (all with tracheostomy) who had been ventilated for $22 \pm 9$ days and transferred to their prolonged-ventilation unit. ${ }^{66}$ With an esophageal balloon they determined the true respiratory rate and compared it to the ventilatormeasured rate, with the difference equal to the number of ineffective efforts. Eight (40\%) of 20 patients had ineffective efforts, constituting $28 \%$ of all breaths (mean of 8 of 28 breaths). The $\mathrm{f} / \mathrm{V}_{\mathrm{T}}$ based on the ventilator-measured rate was 69 breaths/min/L, compared to 96 breaths/min/L with the true respiratory rate. More importantly, 4 of 8 patients had an actual $\mathrm{f} / \mathrm{V}_{\mathrm{T}}>100$ breaths $/ \mathrm{min} / \mathrm{L}$, despite a much lower machine-determined $\mathrm{f} / \mathrm{V}_{\mathrm{T}}$. Although these findings suggest that ineffective efforts may lead to inappropriate attempts at weaning, this remains to be determined. Moreover, whether an $\mathrm{f} / \mathrm{V}_{\mathrm{T}}$ that exceeds 100 breaths $/ \mathrm{min} / \mathrm{L}$ based on ineffective efforts has the same predictive value as one that exceeds 100 breaths/min/L based on effective efforts is unknown. Although it has not been systematically studied, note that both double-triggering and autotriggering will "falsely" elevate the ventilator-measured respiratory rate, leading to an apparently higher $\mathrm{f} / \mathrm{V}_{\mathrm{T}}$.

Efforts to assess patient tolerance for reducing the level of respiratory support or for spontaneous breathing trials should be based on objective clinical criteria, including the respiratory rate. ${ }^{67}$ As noted earlier, a higher level of ventilatory support is associated with an increased percentage of ineffective efforts. For example, suppose at a pressuresupport of $20 \mathrm{~cm} \mathrm{H}_{2} \mathrm{O}$ the number or triggered breaths detected by the ventilator is 12 , and the number of untriggered breaths is 18 , yielding an actual respiratory rate of 30 breaths/min. In an effort to assess patient readiness for weaning, the pressure-support is then reduced to $10 \mathrm{~cm} \mathrm{H}_{2} \mathrm{O}$ resulting in a respiratory rate of 30 breaths/min, with all breaths being triggered. The clinician may conclude the patient is not tolerating the reduction in pressure-support because the respiratory rate increased from 12 breaths $/ \mathrm{min}$ to 30 breaths/min. In fact, in this example, the true respiratory rate was unchanged, suggesting the patient is probably tolerating the lower pressure-support level. Further work is needed to understand how often this phenomenon occurs and whether it delays weaning.

Given the potential effect of patient-ventilator asynchrony on weaning decision making and tolerance for spontaneous breathing trials, does patient-ventilator asynchrony effect weaning outcome? As noted earlier, in patients transferred to a regional weaning unit after 30 days of ventilation, Chao et al found that 19 patients demonstrated ineffective efforts, detected via graphic analysis..$^{48}$ Only $3(16 \%)$ of the 19 successfully weaned from the ventilator, compared to $57 \%$ of those with no ineffective efforts. In addition, those 3 patients took an average of 72 days for successful weaning, compared to 33 days in the group without ineffective efforts. In a preliminary report of medical ICU patients with acute respiratory failure, Tanios et al studied ineffective efforts during spontaneous breathing trials conducted on $7 \mathrm{~cm} \mathrm{H}_{2} \mathrm{O}$ of pressure support. 68 Six of 14 patients demonstrated ineffective efforts, and these patients were more likely to fail the spontaneous breathing trial than the patients without ineffective efforts.

Delay in weaning increases the duration of mechanical ventilation. Several investigators have examined the relationship between patient-ventilator asynchrony and outcomes, including duration of mechanical ventilation, ICU and hospital stay, need for tracheostomy, and survival. In their study with 62 patients, studied an average of 4.5 days after intubation, Thille et al found that patients with an asynchrony index $>10 \%$ had longer duration of mechanical ventilation ( $25 \mathrm{~d}$ vs $7 \mathrm{~d}$ ), were more likely to require more than a week of mechanical ventilation ( $87 \%$ vs $49 \%$ ), and were more likely to receive a tracheostomy (33\% vs 


\section{How Often Does Patient-Ventilator Asynchrony Occur and What Are the Consequences?}

Table 4. Effect of Patient-Ventilator Asynchrony* on Outcomes in an Observational Study ${ }^{47}$

\begin{tabular}{lccc}
\hline \hline & $\begin{array}{c}\text { Ineffective-Effort } \\
\text { Index } \\
>10 \%\end{array}$ & $\begin{array}{c}\text { Ineffective-Effort } \\
\text { Index } \\
<10 \%\end{array}$ & $P$ \\
\hline $\begin{array}{l}\text { Number of patients } \\
\text { Duration of mechanical }\end{array}$ & 16 & 44 & \\
$\quad$ ventilation (median d) & 6 & 2 & $<.05$ \\
28-d ventilator-free & 21 & 25 & $<.05$ \\
$\quad$ survival (median d) & & & \\
ICU stay (median d) & 8 & 8 & $<.05$ \\
Hospital stay (median d) & 21 & 14 & $\mathrm{NS}$ \\
ICU mortality (\%) & 25 & 20 & $\mathrm{NS}$ \\
Hospital mortality (\%) & 30 & & \\
& & & \\
* Patient-ventilator asynchrony was defined as an ineffective-effort index $>10 \%$. & \\
NS = difference not significant & & & \\
\end{tabular}

$4 \%) .{ }^{11}$ There was no statistically significant difference in mortality ( $47 \%$ vs $32 \%)$.

In 60 patients studied during the first day of mechanical ventilation (mean $13 \mathrm{~h}$ after intubation), de Wit and coworkers noted similar findings. ${ }^{47}$ Those with an ineffective triggering index of $>10 \%$ had longer mechanical ventilation, worse 28 -day ventilator-free survival, and longer ICU and hospital stay (Table 4). There were no statistically significant differences in re-intubation, need for tracheostomy, or ICU or hospital mortality. Patients with an ineffective triggering index $>10 \%$ were less likely to be discharged home. In a preliminary study with 30 consecutive medical ICU patients with acute respiratory failure, studied at least 24 hours after intubation, Varon et al examined 24-second tracings every 15 min, times 3 (on average 26 breaths examined). ${ }^{69}$ Asynchrony was detected in 29 patients (97\%), and the mean asynchrony index was $36 \%$. Mortality was higher in patients with an asynchrony index $>30 \%$.

\section{Summary}

Patient-ventilator asynchrony is common, and its prevalence depends on numerous factors, including timing and duration of observation; detection technique; patient population; type of asynchrony; ventilation mode and settings (eg, trigger, flow, and cycle criteria); and confounding factors (eg, state of wakefulness, sedation). Patient-ventilator asynchrony is associated with adverse effects, including increased/wasted WOB, discomfort, increased need for sedation, confusion during the weaning process, prolonged mechanical ventilation, longer ICU and hospital stay, and possibly higher mortality. Whether asynchrony is a marker of poor prognosis or causes these adverse outcomes remains to be determined.

\section{REFERENCES}

1. Reid WD, Huang J, Bryson S, Walker DC, Belcastro AN. Diaphragm injury and myofibrillar structure induced by resistive loading. J Appl Physiol 1994;76(1):176-184.

2. Zhu E, Petrof BJ, Gea J, Comtois N, Grassino AE. Diaphragm muscle fiber injury after inspiratory resistive breathing. Am J Respir Crit Care Med 1997;155(3):1110-1116.

3. Sassoon CS, Caiozzo VJ, Manka A, Sieck GC. Altered diaphragm contractile properties with controlled mechanical ventilation. J Appl Physiol 2002;92(6):2585-2595.

4. Le Bourdelles G, Viires N, Boczkowski J, Seta N, Pavlovic D, Aubier M. Effects of mechanical ventilation on diaphragmatic contractile properties in rats. Am J Respir Crit Care Med 1994;149(6): 1539-1544.

5. Kondili E, Prinianakis G, Georgopoulos D. Patient-ventilator interaction. Br J Anaesth 2003;91(1):106-119.

6. Epstein SK. Optimizing patient-ventilator synchrony. Semin Respir Crit Care Med 2001;22(2):137-152.

7. Jolliet $P$, Tassaux D. Clinical review: patient-ventilator interaction in chronic obstructive pulmonary disease. Crit Care 2006;10(6):236.

8. Dick CR, Sassoon CS. Patient-ventilator interactions. Clin Chest Med 1996;17(3):423-438.

9. Prinianakis G, Kondili E, Georgopoulos D. Patient-ventilator interaction: an overview. Respir Care Clin N Am 2005;11(2):201-224.

10. Racca F, Squadrone V, Ranieri VM. Patient-ventilator interaction during the triggering phase. Respir Care Clin N Am 2005;11(2):225-245.

11. Thille AW, Rodriguez P, Cabello B, Lellouche F, Brochard L. Patient-ventilator asynchrony during assisted mechanical ventilation. Intensive Care Med 2006;32(10):1515-1522.

12. Hill LL, Pearl RG. Flow triggering, pressure triggering, and autotriggering during mechanical ventilation. Crit Care Med 2000;28(2): 579-581.

13. Imanaka H, Takeuchi M, Tachibana K, Nishimura M. Exhaled tidal volume overestimation in mechanically ventilated patients with large cardiogenic oscillation. Crit Care Med 2004;32(7):1546-1549.

14. Kondili E, Xirouchaki N, Georgopoulos D. Modulation and treatment of patient-ventilator dyssynchrony. Curr Opin Crit Care 2007; 13(1):84-89.

15. Thille AW, Lyazidi A, Richard JC, Galia F, Brochard L. A bench study of intensive-care-unit ventilators: new versus old and turbinebased versus compressed gas-based ventilators. Intensive Care Med 2009;35(8): 1368-1376.

16. Richard JC, Carlucci A, Breton L, Langlais N, Jaber S, Maggiore S, et al. Bench testing of pressure support ventilation with three different generations of ventilators. Intensive Care Med 2002;28(8):1049-1057.

17. MacIntyre NR, McConnell R, Cheng KC, Sane A. Patient-ventilator flow dyssynchrony: flow-limited versus pressure-limited breaths. Crit Care Med 1997;25(10):1671-1677.

18. Marini JJ, Capps JS, Culver BH. The inspiratory work of breathing during assisted mechanical ventilation. Chest 1985;87(5):612-618.

19. Marini JJ, Smith TC, Lamb VJ. External work output and force generation during synchronized intermittent mechanical ventilation: effect of machine assistance on breathing effort. Am Rev Respir Dis 1988;138(5):1169-1179.

20. Marini JJ, Rodriguez RM, Lamb V. Bedside estimation of the inspiratory work of breathing during mechanical ventilation. Chest 1986;89(1):56-63.

21. Tobin MJ, Jubran A, Laghi F. Patient-ventilator interaction. Am J Respir Crit Care Med 2001;163(5):1059-1063.

22. Parthasarathy S, Jubran A, Tobin MJ. Assessment of neural inspiratory time in ventilator-supported patients. Am J Respir Crit Care Med 2000;162(2 Pt 1):546-552. 


\section{How Often Does Patient-Ventilator Asynchrony Occur and What Are the Consequences?}

23. Parthasarathy S, Jubran A, Tobin MJ. Cycling of inspiratory and expiratory muscle groups with the ventilator in airflow limitation. Am J Respir Crit Care Med 1998;158(5 Pt 1):1471-1478.

24. Younes M, Brochard L, Grasso S, Kun J, Mancebo J, Ranieri M, et al. A method for monitoring and improving patient: ventilator interaction. Intensive Care Med 2007;33(8):1337-1346.

25. Chen CW, Lin WC, Hsu CH, Cheng KS, Lo CS. Detecting ineffective triggering in the expiratory phase in mechanically ventilated patients based on airway flow and pressure deflection: feasibility of using a computer algorithm. Crit Care Med 2008;36(2):455-461.

26. Giannouli E, Webster K, Roberts D, Younes M. Response of ventilatordependent patients to different levels of pressure support and proportional assist. Am J Respir Crit Care Med 1999;159(6):1716-1725.

27. Moerer O, Beck J, Brander L, Costa R, Quintel M, Slutsky AS, et al. Subject-ventilator synchrony during neural versus pneumatically triggered non-invasive helmet ventilation. Intensive Care Med 2008; 34(9):1615-1623.

28. Tassaux D, Gainnier M, Battisti A, Jolliet P. Impact of expiratory trigger setting on delayed cycling and inspiratory muscle workload. Am J Respir Crit Care Med 2005;172(10):1283-1289.

29. Chiumello D, Polli F, Tallarini F, Chierichetti M, Motta G, Azzari S, et al. Effect of different cycling-off criteria and positive end-expiratory pressure during pressure support ventilation in patients with chronic obstructive pulmonary disease. Crit Care Med 2007;35(11): 2547-2552.

30. Chiumello D, Pelosi P, Taccone P, Slutsky A, Gattinoni L. Effect of different inspiratory rise time and cycling off criteria during pressure support ventilation in patients recovering from acute lung injury. Crit Care Med 2003;31(11):2604-2610.

31. Tokioka H, Tanaka T, Ishizu T, Fukushima T, Iwaki T, Nakamura Y, et al. The effect of breath termination criterion on breathing patterns and the work of breathing during pressure support ventilation. Anesth Analg 2001;92(1):161-165.

32. Kallet RH, Luce JM. Detection of patient-ventilator asynchrony during low tidal volume ventilation, using ventilator waveform graphics. Respir Care 2002;47(2):183-185.

33. Calderini E, Confalonieri M, Puccio PG, Francavilla N, Stella L, Gregoretti C. Patient-ventilator asynchrony during noninvasive ventilation: the role of expiratory trigger. Intensive Care Med 1999; 25(7):662-667.

34. Gurevitch MJ, Gelmont D. Importance of trigger sensitivity to ventilator response delay in advanced chronic obstructive pulmonary disease with respiratory failure. Crit Care Med 1989;17(4):354-359.

35. Ashutosh K, Gilbert R, Auchincloss JH, Jr., Peppi D. Asynchronous breathing movements in patients with chronic obstructive pulmonary disease. Chest 1975;67(5):553-557.

36. Fabry B, Guttmann J, Eberhard L, Bauer T, Haberthur C, Wolff G. An analysis of desynchronization between the spontaneously breathing patient and ventilator during inspiratory pressure support. Chest 1995;107(5):1387-1394.

37. Nava, S, Bruschi, C, Fracchia, C, Braschi, A, Rubini, F. Patientventilator interaction and inspiratory effort during pressure support ventilation in patients with different pathologies. Eur Respir J 1997; 10(1):177-183

38. Thille AW, Cabello B, Galia F, Lyazidi A, Brochard L. Reduction of patient-ventilator asynchrony by reducing tidal volume during pressure-support ventilation. Intensive Care Med 2008;34(8):1477-1486.

39. Jubran A, Van de Graaff WB, Tobin MJ. Variability of patientventilator interaction with pressure support ventilation in patients with chronic obstructive pulmonary disease. Am J Respir Crit Care Med 1995;152(1):129-136.

40. Leung P, Jubran A, Tobin MJ. Comparison of assisted ventilator modes on triggering, patient effort, and dyspnea. Am J Respir Crit Care Med 1997;155(6):1940-1948.
41. Pohlman MC, McCallister KE, Schweickert WD, Pohlman AS, Nigos CP, Krishnan JA, et al. Excessive tidal volume from breath stacking during lung-protective ventilation for acute lung injury. Crit Care Med 2008;36(11):3019-3023.

42. Vignaux L, Vargas F, Roeseler J, Tassaux D, Thille AW, Kossowsky MP, et al. Patient-ventilator asynchrony during non-invasive ventilation for acute respiratory failure: a multicenter study. Intensive Care Med 2009;35(5):840-846.

43. Mulqueeny, Q, Redmond, SJ, Tassaux, D, Vignaux, L, Jolliet, P, Ceriana, $\mathrm{P}$, et al. Automated detection of asynchrony in patientventilator interaction. Conf Proc IEEE Eng Med Biol Soc 2009; 2009:5324-5327.

44. Colombo D, Cammarota G, Bergamaschi V, De Lucia M, Corte FD, Navalesi P. Physiologic response to varying levels of pressure support and neurally adjusted ventilatory assist in patients with acute respiratory failure. Intensive Care Med 2008;34(11): 2010-2018

45. Spahija J, de Marchie M, Albert M, Bellemare P, Delisle S, Beck J, et al. Patient-ventilator interaction during pressure support ventilation and neurally adjusted ventilatory assist. Crit Care Med 2010; 38(2):518-526.

46. Xirouchaki N, Kondili E, Vaporidi K, Xirouchakis G, Klimathianaki M, Gavriilidis G, et al. Proportional assist ventilation with load-adjustable gain factors in critically ill patients: comparison with pressure support. Intensive Care Med 2008;34(11):20262034.

47. de Wit M, Miller KB, Green DA, Ostman HE, Gennings C, Epstein SK. Ineffective triggering predicts increased duration of mechanical ventilation. Crit Care Med 2009;37(10):2740-2745.

48. Chao DC, Scheinhorn DJ, Stearn-Hassenpflug M. Patient-ventilator trigger asynchrony in prolonged mechanical ventilation. Chest 1997; 112(6):1592-1599.

49. Fanfulla F, Taurino AE, Lupo ND, Trentin R, D’Ambrosio C, Nava $\mathrm{S}$. Effect of sleep on patient/ventilator asynchrony in patients undergoing chronic non-invasive mechanical ventilation. Respir Med 2007; 101(8):1702-1707.

50. Bosma K, Ferreyra G, Ambrogio C, Pasero D, Mirabella L, Braghiroli A, et al. Patient-ventilator interaction and sleep in mechanically ventilated patients: pressure support versus proportional assist ventilation. Crit Care Med 2007;35(4):1048-1054.

51. Vitacca M, Bianchi L, Zanotti E, Vianello A, Barbano L, Porta R, et al. Assessment of physiologic variables and subjective comfort under different levels of pressure support ventilation. Chest 2004;126(3): 851-859.

52. de Wit M, Pedram S, Best AM, Epstein SK. Observational study of patient-ventilator asynchrony and relationship to sedation level. J Crit Care 2009;24(1):74-80.

53. Hunter KD, Faulkner JA. Pliometric contraction-induced injury of mouse skeletal muscle: effect of initial length. J Appl Physiol 1997; 82(1):278-283.

54. Devor ST, Faulkner JA. Regeneration of new fibers in muscles of old rats reduces contraction-induced injury. J Appl Physiol 1999;87(2): 750-756.

55. Willatts SM, Drummond G. Brainstem death and ventilator trigger settings. Anaesthesia 2000;55(7):676-677.

56. Nava S, Bruschi C, Rubini F, Palo A, Iotti G, Braschi A. Respiratory response and inspiratory effort during pressure support ventilation in COPD patients. Intensive Care Med 1995;21(11): 871-879.

57. Ventilation with lower tidal volumes as compared with traditional tidal volumes for acute lung injury and the acute respiratory distress syndrome. The Acute Respiratory Distress Syndrome Network. N Engl J Med 2000;342(18):1301-1308. 
58. Kallet RH, Campbell AR, Dicker RA, Katz JA, Mackersie RC. Effects of tidal volume on work of breathing during lung-protective ventilation in patients with acute lung injury and acute respiratory distress syndrome. Crit Care Med 2006;34(1):8-14.

59. Kollef MH, Levy NT, Ahrens TS, Schaiff R, Prentice D, Sherman G. The use of continuous i.v. sedation is associated with prolongation of mechanical ventilation. Chest 1998;114(2):541-548.

60. de Wit M, Gennings C, Jenvey WI, Epstein SK. Randomized trial comparing daily interruption of sedation and nursing-implemented sedation algorithm in medical intensive care unit patients. Crit Care 2008;12(3):R70.

61. Brook AD, Ahrens TS, Schaiff R, Prentice D, Sherman G, Shannon $\mathrm{W}$, et al. Effect of a nursing-implemented sedation protocol on the duration of mechanical ventilation. Crit Care Med 1999;27(12):26092615.

62. Kress JP, Pohlman AS, O'Connor MF, Hall JB. Daily interruption of sedative infusions in critically ill patients undergoing mechanical ventilation. N Engl J Med 2000;342(20):1471-1477.

63. Tanios MA, Nevins ML, Hendra KP, Cardinal P, Allan JE, Naumova $\mathrm{EN}$, et al. A randomized, controlled trial of the role of weaning predictors in clinical decision-making. Crit Care Med 2006;34(10): 2530-2535.

64. Yang KL, Tobin MJ. A prospective study of indexes predicting the outcome of trials of weaning from mechanical ventilation. N Engl J Med 1991;324(21):1445-1450.

65. El-Khatib MF, Zeineldine SM, Jamaleddine GW. Effect of pressure support ventilation and positive end expiratory pressure on the rapid shallow breathing index in intensive care unit patients. Intensive Care Med 2008;34(3):505-510.

66. Purro A, Appendini L, De Gaetano A, Gudjonsdottir M, Donner CF, Rossi A. Physiologic determinants of ventilator dependence in longterm mechanically ventilated patients. Am J Respir Crit Care Med 2000;161(4 Pt 1):1115-1123.

67. Epstein SK. Weaning from ventilatory support. Curr Opin Crit Care 2009;15(1):36-43.

68. Tanios, M, Singh, N, Hassoun, P, Epstein, S. Patient-ventilator trigger asynchrony during weaning from mechanical ventilation (abstract). Am J Respir Crit Care Med 2002;165(Suppl):A687.

69. Varon, J, Fromm, R, Rodarte, J, Reinoso, M. Prevalence of patient ventilator asynchrony in critically ill patients. Chest 1994;106(Suppl):141S.

\section{Discussion}

Kacmarek: Scott, it seems that the majority of the studies you discussed were from medical patients, not surgical patients. Are there any data or studies that dealt with patients and asynchrony in the surgical ICU [intensive care unit]? Or is this primarily of concern in medical patients, who have a greater tendency of having multiple comorbidities and in general a longer course of mechanical ventilation?

Epstein: Among the studies I showed, there is a proportion of patients who are postoperative, including in the Vitacca study, ${ }^{1}$ which was a study of patients ventilated for at least 30 days, and the Nava study ${ }^{2}$ of patients ventilated for just 48 hours. The Nava study showed less asynchrony in postoperative patients than in COPD. The Vitacca study showed the same amount of asynchrony, as compared to patients with COPD and neuromuscular disease. Patients who had been ventilated for 30 days are a completely different category of patient. I don't know of any studies of the first 48 hours in the surgical ICU.
1. Vitacca M, Bianchi L, Zanotti E, Vianello A, Barbano L, Porta R, Clini E. Assessment of physiologic variables and subjective comfort under different levels of pressure support ventilation. Chest 2004; 126(3):851-859.

2. Nava S, Bruschi C, Fracchia C, Braschi A, Rubini F. Patient-ventilator interaction and inspiratory effort during pressure support ventilation in patients with different pathologies. Eur Respir J 1997;10(1):177183.

Branson: After we were asked to write the editorial ${ }^{1}$ about your paper, ${ }^{2}$ we decided to evaluate asynchrony in trauma patients. We recorded two 30 minute periods of airway pressure, volume, and flow data. The first measurement was made during the initial 24 hours of ventilatory support. The second was measured on the first day the patients were triggering more than $50 \%$ of their breaths. We found very little asynchrony; not surprisingly, we generally see few patients with trauma and COPD. COPD patients represent the group with the most common asynchrony, missed triggers.

We've done almost 30 patients and found that early in their postoperative course where the effects of anesthesia are present, asynchrony is more com- mon. During the first 24 hours, the presence of hypoxemia results in higher levels of PEEP being used and commonly pressure targeted ventilation with a prolonged inspiratory time. As the patients awaken, the longer inspiratory time results in asynchrony due to a mismatch between the patient's and the ventilator's inspiratory timing. During this time the patients are commonly on synchronized intermittent mandatory ventilation (SIMV). This could be avoided by staff recognition and adjustment of inspiratory time or switching the patient to pressure support alone.

The one thing that does impress me is that even elderly patients with obvious air-trapping (evaluated by the flow waveform-we are not using esophageal manometry) are able to overcome the air-trapping and avoid missed triggers during periods of tachypnea. I think this occurs because the patients do not have the mechanical disadvantages of patients with COPD and have the muscle strength to trigger every breath.

1. Robinson, Bryce RH, Branson, Richard D. Consequences of ventilator asynchrony: why 
can't we all get along? (editorial). Crit Care Med 2009;37(10):2848-2849.

2. de Wit M, Miller KB, Green DA, Ostman HE, Gennings C, Epstein SK. Ineffective triggering predicts increased duration of mechanical ventilation. Crit Care Med 2009;37(10):2740-2745.

Kacmarek: Do you get any sense that those who fall into this category require a prolonged weaning period, or that their recovery from the acute episode is prolonged because of the asynchrony?

Branson: I don't know if we know that yet, or that we have looked at it long enough to tell. It may be that we have too few patients with an asynchrony index $>10 \%$ to make any worthwhile estimates. Another problem we have noticed is the insistence of the respiratory therapists to use adaptive pressure ventilation (AutoFlow) in most patients. I am not sure why, but during AutoFlow with SIMV, the ventilator will allow a mandatory breath to be delivered on top of a spontaneous breath (often times a pressure targeted time cycled breath on top of a pressure targeted flow cycled breath). This breath stacking gives the pressure waveform the appearance of a stair step. I think the reason this is allowed is that the breaths are pressure limited, so unlike volume ventilation where the set tidal volume is delivered on top of a spontaneous breath resulting in a further increase in tidal volume, the pressure limited breath prevents excess volume by nature of operation. This does however, often result in a prolonged inspiratory time. The principal investigator of these studies, Bryce Robinson, has a particular interest in delirium and wants to evaluate delirium in surgical patients and the impact on asynchrony.

Epstein: I don't think that's what Marjolein found in her analysis. I think she found that the patients who were in coma had ineffective triggers. de Wit: That's right, Scott. The patients were grouped into 3 categories: with delirium, without delirium, and comatose (and thus the presence or absence of delirium cannot be determined). The comatose patients had more ineffective triggering than the other 2 groups. However, there was no difference in ineffective triggering between the patients with and without delirium.

Branson: When you say comatose, do you mean coma due to heavy sedation or some other cause?

de Wit: Making a diagnosis of coma and the presence or absence of delirium does not reveal the etiology of the neurocognitive state. I don't know if it's necessarily all sedation-related. It may be that these people could just have a vegetative delirium because of some other process. It's not necessarily due to medication.

Younes:" You mentioned the confusion that can arise sometimes from ineffective efforts during weaning. I think all of us have seen patients who continue to breathe fast despite being very well assisted and making very small efforts, and yet they're breathing at 35 or even 50 breaths a minute. I want to propose an approach to the group. When you turn down the pressure support and the ventilator rate goes up, and you turn the pressuresupport level back up again and the ventilator rate goes back down again and the patient is very comfortable, then slow down the speed on the oscilloscope so you can see many breaths in one sweep, and then suddenly change the pressure-support from the high level to the level that previously caused the ventilator rate to jump up. If the ventilator rate increases immediately upon pushing the button, say

\footnotetext{
* Magdy Younes MD FRCP(C) PhD, Departmet of Medicine, University of Manitoba, Winnipeg, Manitoba, Canada.
}

from 20 to 15 , or 15 to 10 , then that is the patient's inherent rate and does not reflect any distress, because distress cannot happen in one breath of under-assist.

Epstein: Just to clarify, what you're saying is that if this was a different mechanism, no distress, more of a gradual increase?

Younes: Well, since it happens instantly.

Epstein: Right, it makes sense. That would be interesting to look at.

Parthasarathy: You really hit the nail on the head when you talked about whether patient-ventilator asynchrony is actually a marker or phenomenon of the comorbid disease such as COPD, or whether it's independently injurious to the patient's respiratory muscles. You proposed that we haven't answered that question and that it would probably need a trial. How would you design that trial?

Epstein: I was afraid you were going to ask that. There are so many confounding variables, it would be an extraordinarily difficult trial to do. I've alluded to this before: it's hard to assure synchrony at the bedside, because you could spend hours, and then the patient's condition changes and the settings you worked so hard to derive become irrelevant 10 or 15 minutes later. This is where I think you would need to study conventional ventilation modes and compare them to closedloop modes that make these adjustments without relying on the clinician. It wouldn't be pressure support versus pressure support with 2 different approaches; it'd be pressure support versus one of the closed-loop algorithms. Then you'd have to document that the closed-loop form truly led to less asynchrony.

Sassoon: Have you come across anything on the effects of bronchodilators 
on patient-ventilator asynchrony? As you know, one of the determinants of asynchrony is dynamic hyperinflation. If you administer bronchodilators, would that resolve or at least ameliorate ineffective triggering? Along with Magdy's comments, when a patient's inherent respiratory rate increases as the pressure-support level is reduced, the inspiratory-expiratory ratio is probably altered from, for instance, 1:2 to $1: 1$. Doesn't that in effect induce greater dynamic hyperinflation?

Epstein: I don't know specifically about bronchodilators, but an analogous study looked at the physiology of tracheostomy and found that the reduced resistance of a tracheostomy tube improves patient-ventilator interaction. In that study, which was by a French group, replacing an endotracheal tube with a tracheostomy reduced airways resistance and led to fewer ineffective trigger breaths. ${ }^{1}$ Presumably, one reason is the reduction in dynamic hyperinflation because respiratory resistance has gone down. I don't know of a specific study that used bronchodilators, and none certainly that gives any prevalence data. Maybe there is a small physiological study.

1. Diehl JL, El Atrous S, Touchard D, Lemaire F, Brochard L. Changes in the work of breathing induced by tracheotomy in ventilator-dependent patients. Am J Respir Crit Care Med 1999;159(2):383-388.

Gentile: We're all showing data from the past, but is the problem getting better or worse? Or are we simply recognizing it more? Several of us in this room have been in the business for a long time and we were around when graphics was an optional package for a ventilator. Prior to graphics on every ventilator we just saw the patient fighting the ventilator and then a nurse would run in with a slug of sedation and the patient became more synchronous because they're unconscious. At the AARC [American As- sociation for Respiratory Care] Congress and other meetings, graphics is still a very popular topic. Is dyssynchrony more prevalent now? Is it getting better or worse?

Epstein: I don't think it's more prevalent. I think we're now recognizing it. As a fellow in 1989, I trained with a group that had little interest in mechanical ventilation. At the bedside, even where ventilators with graphics were available, we never looked at them. Some people just aren't as interested in mechanical ventilation, and if you don't take the time to look at the graphics, you will not see it. I think it's an issue of us recognizing it. We don't have good data to say whether the incidence has changed or not. One would hope that it's improved, because we now, as Rich alluded to, have much better triggering mechanisms. We have additional options for cycling that we didn't have before. So I would hope that it's better, but we don't have any proof.

Pierson: This is not a question, but more an observation. Even at this early stage in our conference I see a couple of themes emerging. One, of course, is the complexity of the whole thing, but the other one that's striking me already is the importance of clinician behavior to what happens to our patients. This relates to what Bob Kacmarek said about the need for education. The patient has tachypnea so the nurse administers more sedation because it is interpreted as patient distress. We do tracheostomies to facilitate weaning because it changes our behavior and the way we try to get the patient off the ventilator. This harkens back to the 2 big multicenter weaning trials in Europe, ${ }^{1,2}$ both of which showed that when candidate patients who were assumed to be difficult to wean were actually allowed to breathe spontaneously for 2 hours, two thirds of them were found to be already ready for extubation.
This is a complicated issue: one not easy to recognize and not easy to deal with when it is recognized. The outcomes of patients on mechanical ventilators seem so dramatically affected by how the clinicians caring for them behave-how they proceed through the protocols, how they do sedation vacations, how they decide when to change the settings or start weaningthat it makes interpreting the studies all the more difficult. The current area of emphasis on knowledge-translation, and how we're going to get what we know into the actual behavior of clinicians, is beginning to address this, ${ }^{3}$ but it strikes me already that that is a big challenge for our conference.

1. Brochard L, Rauss A, Benito S, Conti G, Mancebo J, Rekik N, et al. Comparison of 3 methods of gradual withdrawal from ventilator support during weaning from mechanical ventilation. Am J Respir Crit Care Med 1994;150(4):896-903.

2. Esteban A, Frutos F, Tobin MJ, Alía I, Solsona JF, Valverdú I, et al. A comparison of 4 methods of weaning patients from mechanical ventilation. Spanish Lung Failure Collaborative Group. N Engl J Med 1995;332(6):345-350.

3. Pierson DJ. Translating evidence into practice. Respir Care 2009;54(10):1386-1401.

\section{Epstein: Agreed.}

Hurford: Two other comments, to complicate things a bit more. We're emphasizing the ventilator, but you brought up the concept of the airway and the endotracheal tube replaced by a tracheostomy. Half the time tracheostomy tubes are out of place, suggesting that airway patency and the type of airway we're using may be very important. ${ }^{1}$ The electronics of the mechanical ventilator are important but may not be the critical issue here.

You emphasized that these physiologic changes may affect the ability to wean, or perhaps even mortality. We need a hypothesis of why that is, and to provide a hypothesis I'd like to suggest going back to some work done in the 1980 s on cardiopulmonary interactions, which suggested that having 
people make ventilatory efforts against a mechanical ventilator is not good for the heart and can set up a cycle of subclinical myocardial ischemia, heart failure, and fluid retention. ${ }^{2}$ Patients who are fighting the ventilator might also be fighting to have adequate cardiac function.

1. Schmidt U, Hess D, Kwo J, Lagambina S, Gettings E, Khandwala F, et al. Tracheostomy tube malposition in patients admitted to a respiratory acute care unit following prolonged ventilation. Chest 2008; 134(2):288-294.

2. Hurford WE. Cardiopulmonary interactions during mechanical ventilation. Int Anesthesiol Clin 1999;37(3):35-46.

Epstein: I like that hypothesis. In patients who have delayed cycling with the ventilator, leading to increased dynamic hyperinflation, that would di- rectly affect cardiopulmonary performance. What I don't know is whether the ineffective efforts themselves do something to the heart, by changing thoracic pressure, or increasing the work of breathing, or diverting blood flow to the respiratory muscles. That's an interesting hypothesis. There's increasing interest in how often patients fail weaning because of a cardiac issues, and maybe this is an area for additional observational studies.

It'd be hard to study, but I think that asynchrony does affect the duration of ventilation, because it leads us to use information incorrectly. Here's an analogy. In the ICU we often put in pulmonary artery catheters in patients who have liver failure and renal failure: is it prerenal azotemia, or hepatorenal syndrome? When we put those catheters in, $95 \%$ of those patients have a pulmonary artery occlusion pressure above $20 \mathrm{~mm} \mathrm{Hg}$. But is it 20 because they are volume-overloaded or because intrathoracic pressure is abnormally high because they've got a large volume of ascites? In the first instance we might give diuretics, but in the second we might give fluids! It may be the same kind of thing here, where we get confused with the information when asynchrony is present. Is the respiratory rate 10 breaths a minute, or is it 30 ?

I am also intrigued about the potential for injuring respiratory muscles with eccentric contraction. There's very clear literature about this happening in skeletal muscles in the thigh, which release cytokines when you injure them. I don't know of any data from animal studies on whether eccentric contractions can injure the diaphragm.

This article is approved for Continuing Respiratory Care Education credit. For information and to obtain your CRCE

(free to AARC members) visit

RCJournal.com

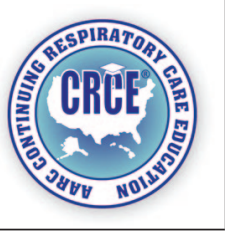

